\title{
Epidemiology, Treatment and Microbiological Surveillance of SARS-CoV-2
}

\author{
Manikant Tripathi ${ }^{1}$ and Shailendra Kumar ${ }^{1^{*}}$ \\ ${ }^{1}$ Department of Microbiology, Centre of Excellence, Dr. Rammanohar Lohia Avadh University, \\ Ayodhya, U.P., 224001, India.
}

\begin{abstract}
Authors' contributions
This work was carried out in collaboration between both authors. Author MT managed the literature searches and wrote the first draft of the manuscript. Author SK initiated the concept and revised the draft thoroughly for intellectual interpretation. Both authors read and approved the final manuscript.
\end{abstract}

Article Information

DOI: 10.9734/ARRB/2020/v35i530230

Editor(s):

(1) Dr. Md. Torequl Islam, Federal University of Piaui, Brazil. (1) Hayder M. Al-kuraishy, Al-Mustansiriya University, Iraq. (2) Mamoun Al-Qaseer, Kuwait Institute for Medical Specialization, Kuwait.

(3) Kapil Amgain, Karnali Academy of Health Sciences, Nepal. Complete Peer review History: http://www.sdiarticle4.com/review-history/57987

Review Article

Received 27 May 2020

Accepted 13 June 2020

Published 26 June 2020

\begin{abstract}
Coronaviruses (CoV) belong to Coronaviridiae family that cause deadly diseases in humans or animals. These viruses are enveloped and have single stranded positive-sense large RNA genome. Severe Acute Respiratory Syndrome-Coronavirus-2 (SARS-CoV-2) causes deadly pandemic coronavirus disease-2019 (COVID-19) in humans. It is affecting every aspect of humans' daily life. The symptoms of COVID-19 include fever, loss of smell, shortness of breath, cough, muscles pain, chest pain, and kidney failure that occurs in severe conditions. The virus has spread throughout the world. In India, the estimated number of infected people is more than 1.5 lakh with less fatality rate $2.87 \%$ on May 27, 2020 as per the Ministry of Health and Family Welfare data. The studies suggest that virus has been considered descended from the previous viruses as severe acute respiratory syndrome corona virus (SARS-CoV), Middle East respiratory syndrome virus (MERS) human and bat corona viruses. Currently, vaccine developments are under clinical trials. The management of emerging infectious diseases is a challenging task. It requires much improved microbiological surveillance system to track and predict the virus infections. The proper study and predictions based on screening of various sources of infection may help us to manage the challenging infections in future. The present review summarizes the characteristics of virus, disease symptoms, epidemiology, transmission, treatment and microbiological surveillance of pandemic COVID-19.
\end{abstract}


Keywords: Coronavirus; COVID-19; microbiological surveillance; pandemic; SARS-CoV-2.

\section{INTRODUCTION}

Coronaviruses belongs to the family Coronaviridae of the order Nidovirales. The virus is large, enveloped and has high mutation rates [1]. The first characterized human coronavirus in 1960, caused upper respiratory tract infections in children [2]. As per the World Health Organization (WHO), SARS-CoV-2 has so far affected millions of people globally, individuals of all ages. Coronaviruses cause respiratory, gastrointestinal and hepatic infections in human and animals [3,4]. The pathogenic coronavirus (CoV) appeared in 2002, causing severe acute respiratory syndrome (SARS) and the Middle East respiratory syndrome coronavirus (MERS-CoV) emerged as an epidemic in the Middle East in 2012 [5].

Lai and Holmes [6] reported that human and animal coronavirus are categorized into 3 groups based on their antigenic properties and genetic make-up. Viruses such as 229E, OC43 and avian infectious viruses are members of group I, II and III, respectively [6]. There are four main sub-groups of coronaviruses, known as alpha, beta, gamma and delta (https://www.cdc.gov/coronavirus/types.html).

The recently reported member of coronavirus has been identified as a new member of beta coronaviruses with nearly $79 \%$ genetic similarity with SARS-CoV [7].

The first case of coronavirus disease was reported in December, 2019 from wet animal market, Wuhan City, China [8]. On the basis of initial epidemiological investigations, the pneumonia-like cases have been linked to a seafood and animal market in Wuhan that might point to a zoonotic origin of the new coronavirus according to the United States Centers for Disease Control and Prevention (CDC). This virus is global threat and challenge for every individual of planet earth. COVID-19 has been declared a pandemic disease by WHO on 11 March 2020. The coronaviruses are single-stranded, positive-sense RNA viruses with a 5'-cap structure and 3'-poly-A tail [1]. The genomic sequence for SARS-CoV-2 was available to public databases on January 10, 2020 [9]. The genetic study showed that SARS-CoV-2 have a typical genome structure and assigned to the cluster of betacoronaviruses (such as SARS-CoV, MERS-CoV, BAT-SARS) [4].
Four structural proteins viz., spike, membrane, envelope and nucleoproteins in coronaviruses are required for their assembly and infectivity. The virus diameter is approximately $120 \mathrm{~nm}$ [4]. COVID-19 is a global challenge and public health emergency. The global solidarity is very important for getting victory against this pandemic disease. Microbiological disease surveillance, case finding, contact tracing and mass communication campaigns to affected people would also be the possible strategies for eradicating COVID-19 pandemic.

The present review is an overview of symptoms, transmission, epidemiology, recent developments in treatment and microbiological surveillance strategies for COVID-19 infection.

\section{STRUCTURE OF CORONAVIRUS}

Coronaviruses are approximately $60-140 \mathrm{~nm}$ in diameter and pleomorphic spherical particles [10]. The virion envelop consists of three main proteins on the surface spike (S), membrane (M) and envelop (E) [11]. The nucleocapsid (N) protein is present in the virus envelope bound with positive-sense single-stranded RNA genome [12]. The envelope and nucleocapsid proteins protect the virus when it is outside the host cell [11]. Zheng et al. [13] reported that coronaviruses involves two major steps, receptor binding and membrane fusion in cell entry. Membrane fusion requires activation by host proteases which play important roles in coronavirus entry. It is imperative to understanding the structure of the virus for identifying possible drug targets, and developing effective medicines [14].

\section{SYMPTOMS OF COVID-19}

According to the WHO, the symptoms of COVID19 are fever, headache, dry cough, tiredness, sore throat, diarrhea and loss of taste or smell [15]. In general, it may appear within 2-14 days after exposure to the coronavirus [16]. These symptoms are usually mild and begin gradually. People of all ages are affected with COVID-19 infection. But, the older people and those with health problems such as diabetes, high blood pressure, cancer, heart and lung problems are at higher risk. According to the CDC and $\mathrm{WHO}$, in severe cases of coronavirus infection could lead to kidney failure and death $[15,16]$. The 
symptoms of coronavirus infection are showed in Fig. 1.

\section{TRANSMISSION}

The COVID-19 infection spread through personto-person contact, as well as through coughing, sneezing, or even talking with infected people (Fig. 2). People may get infected with COVID-19 from others who are already infected with SARS$\mathrm{CoV}-2$ virus. The virus released in respiratory secretions of patients, enters the healthy host through inhalation, and passes into the mucus membranes. While, the respiratory droplets are relatively heavy, do not travel distant and rapidly go down to the ground [15]. The schematic spread of virus is shown in Fig. 2.

The virus structural proteins play important role for its transmission in humans. The spike proteins in Coronaviruses attaches to human cells membrane (US CDC).

\section{SENSITIVITY OF SARS-CoV-2}

There are environmental factors that may affect the survival of the deadly coronaviruses. Doremalen et al. [17] reported that the stability of coronavirus strains SARS-CoV-2 nCoV-WA12020 and SARS-CoV-1 Tor2 in aerosols and on various surfaces and also evaluated their decay rates using the Bayesian regression model. They found that the SARS-CoV-2 remained viable in aerosols throughout the study duration (for $3 \mathrm{~h}$ ), it's titer is reduced drastically on plastics in $72 \mathrm{~h}$ from $10^{3.4}$ to $10^{0.7}$ tissue culture infectious dose (TCID) per milliliter, and on stainless steel in $48 \mathrm{~h}$ from $10^{3.6}$ to $10^{0.6}$ TCID per milliliter. The report suggests no viable SARS-CoV-2 after $4 \mathrm{~h}$ on copper while SARS-CoV-1 was not viable beyond $8 \mathrm{~h}$ [17]. Kahn and Mclntosh [2] reported that in temperate climates, respiratory coronavirus infections are more common in the winter compared to the summer. Chan et al. [18] studied the effects of temperature and relative humidity on the viability of the SARS coronavirus. They observed that the virus could remain active and viable for more than 5 days at $22-25^{\circ} \mathrm{C}$ with the relative humidity of 40 to $50 \%$. However, the virus rapidly loses its viability at higher temperature $\left(38^{\circ} \mathrm{C}\right)$ and relative humidity of $>95 \%$. The researchers also reported that infectivity of SARS-CoV was lost after heating at $56^{\circ} \mathrm{C}$ for $15 \mathrm{~min}$ [18]. Whereas, Altamimi and Ahmed [19] reported that the Middle East respiratory syndrome coronavirus (MERS-CoV) is affected by climatic conditions with increasing incidence between April and August.

\section{EPIDEMIOLOGY OF COVID-19}

SARS-CoV-2 is zoonotic in origin. Presumably, this virus spread from seafood and wet animal wholesale market, Wuhan, Hubei Province, China. Pneumonia of unknown cause detected in Wuhan, China was first reported by the World Health Organization (WHO) on December 31, 2019 [20]. The number of SARS-CoV-2 infected people rose rapidly in most part of the world. More than 210 countries of the world are suffering from this deadly virus according to the WHO data. Worldwide, there have been $5,48,8825$ confirmed cases of COVID-19 and 3,43,562 deaths on 27 May, 2020 [21].

India fights against COVID-19 outbreak seem to be successful. The most important factor of this success is the complete lockdown of the country on time by the honorable Prime Minister and the effective preventive guidelines issued timely by the Ministry of Health and Family Welfare. In India, Social distancing is maintained by closing restaurants, hotels, malls, sports gathering, colleges and universities campuses. The school, colleges and universities have moved to online teaching during the lockdown in India. These all measures may restrict the virus spread at community level.

Currently, In India, there are 83004 active, 64425 recovered, 4337 deaths and 1 migrant case on May 27, 2020 according to Ministry of Health and Family Welfare data. Almost every state and union territory of India is affected by the pandemic COVID-19. The mortality rate is approximately $3 \%$ out of total infected people in India (https://www.mohfw.gov.in). More than 50\% COVID-19 cases were reported (by May 27, 2020) mainly in the four states (Maharashtra, Delhi, Gujrat, Tamil Nadu) of India. However, there is no case of COVID-19 in some states of India like Lakshdweep, Daman and Diu. It might be due to proper following of the preventive advisories issued by the Ministry of Health and Family Welfare, India. The presence of a furin-like cleavage site in SARS-CoV-2 facilitates the $S$ protein priming and might increase the efficiency of the spread of SARSCoV-2 as compared to other beta coronaviruses [22].

The patients, those experience severe infections, present the clinical symptoms associated with 


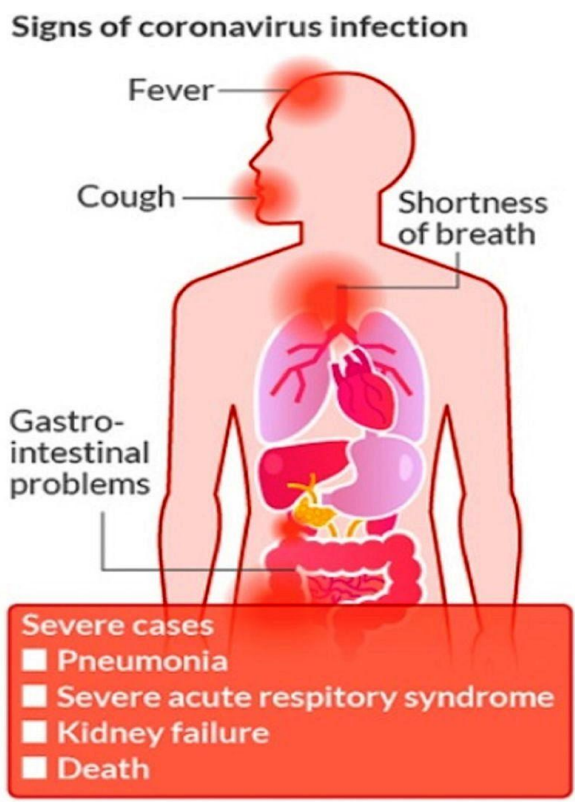

Fig. 1. Symptoms of coronavirus infection in severe cases (Source: WHO, CDC)

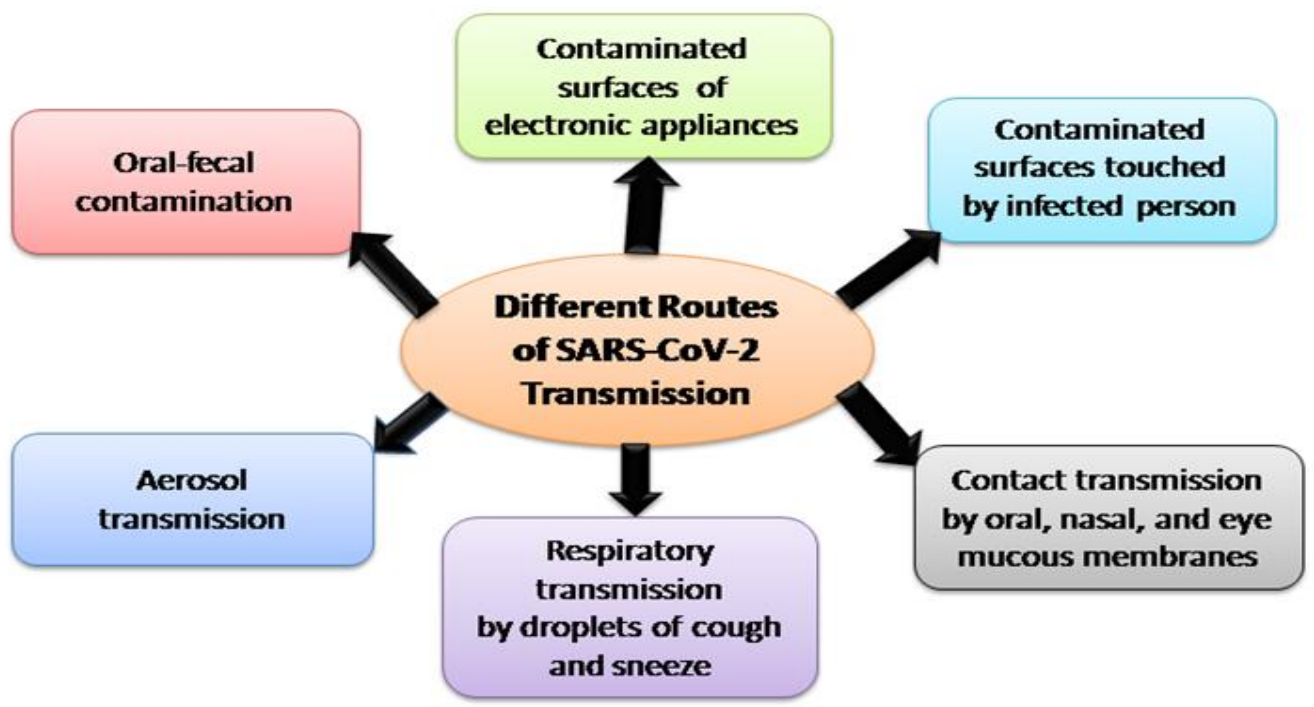

Fig. 2. Different modes of SARS-CoV-2 spread in humans

pneumonia. It appears that mostly infected people experience no symptoms or symptoms associated with mild pneumonia, some suffer from a severe form of the disease, and some are critical with respiratory failure, shock, and multi organ dysfunction $[1,20]$. In India, mostly symptomatic patients are tested for the diagnosis of SARSCoV-2. However, it is also important to perform maximum number tests to diagnose the infected people who don't show any symptoms of COVID-
19. SARS-CoV-2 infects individuals of all age group. Healthy people tend to be asymptomatic or experience only mild forms of the disease. Most severe and critical cases have occurred in elderly people and people with compromised immune systems (i.e., that are already fighting other diseases and disorders). Gralinski and Baric [23] reviewed the molecular pathology of emerging coronavirus infections. They reported that more than $50 \%$ mortality rates were seen in the aged 
and immune suppressed populations. The Government of India has launched an Android based application, i.e., Arogya Setu App, which may be helpful in COVID-19 detection and spread through contact tracing and follow-up of contacts in country.

\section{TREATMENTS}

The virus pandemic is a big challenge, globally. Every country is working on development of therapeutics and vaccines against SARS-CoV-2. It is the utmost importance for any nation to develop the fighter molecule for eradicating this deadly viral disease. In India, ICMR will begin a study to test the efficacy of Bacille CalmetteGuerin (BCG) vaccine in preventing COVID-19. Some researchers also hypothesized that antimalarial drugs, regular BCG vaccination and higher temperature may decrease the infectivity of COVID-19 disease [24].

Several Indian companies such as Bharat Biotech, Serum Institute of India, Indian Immunological, Cadila Healthcare and Mynvax are working to develop COVID-19 vaccines. Most of the vaccine candidates are already in the animal trial phase. It is expected that India may have vaccine by 2021. Whereas, Le et al. [25] reported that the most advanced candidates for vaccines have recently moved into clinical trials, including mRNA-1273 from Moderna, Ad5nCoV from CanSino Biologicals, INO-4800 from Inovio, LV-SMENP-DC and pathogen-specific aAPC from Shenzhen Geno-Immune Medical Institute (ClinicalTrials.gov, WHO).

However, there are many well-known antiviral drugs such as lopinavir/ritonavir are also tested for possible treatment for COVID-19 [26]. Xia et al. [27] reported that the inhibition of SARS-CoV-2 infection by a highly potent pan-coronavirus fusion inhibitor targeting its spike protein that harbors a high capacity to mediate membrane fusion. Phytochemicals and natural products can be used to inhibit various steps in viral infection and replication, i.e., resveratrol has been used to inhibit MERS-CoV replication [28], suggesting that resveratrol may also be effective against COVID-19 infection. Kampf et al. [29] reported that human coronavirus ( $\mathrm{HCoV})$ can be inactivated by using many chemicals such as 62$71 \%$ ethanol, $0.5 \%$ hydrogen peroxide or $0.1 \%$ sodium hypochlorite, $0.05 \%-0.2 \%$ benzalkonium chloride or $0.02 \%$ chlorohexidine digluconate. Another approach involves use of antibodies extracted from recovered patients. Plasma- therapy seems to be effective against SARS infections [30].

Ali and Yasin [31] reported that ACE 2 acts a receptor for Spike S1 protein of SARS-CoV-2. The understanding of the cytokine storm mechanism is also important for developing effective therapeutics for COVID-19. Rahmati and Moosavi [32] discussed about the cytokinetargeted therapy in severely ill COVID-19 patients.

The joint initiative of Ministry of AYUSH and Health, Government of India and Council of Scientific and Industrial Research (CSIR) with Indian Council of Medical Research (ICMR) conducted clinical trials to assess the efficacy of ayurvedic drug Ashwagandha as a preventive intervention among high-risk coronavirus infected population and some others ayurvedic drugs like Yashtimadhu (Mulethi), Pippali and Giloy are also being evaluated for their efficacy repurposing is going on. Kumar et al. [33] examined the binding potential of withanone (active withanolides of Ashwagandha) and caffeic acid phenethyl ester (bioactive ingredient of propolis) to a highly conserved protein, $\mathrm{M}^{\text {pro }}$ of SARS-CoV-2. They found that these natural compounds may possess the potential to inhibit the functional activity of SARS-CoV-2 proteases which offers therapeutic value for the management of novel fatal coronavirus disease [33]. Thus, the Indian tradition Ayurveda can become booster in COVID-19 treatment.

\section{DISEASE SURVEILLANCE}

Pandemic of SARS-CoV2 started in Wuhan, China during December 2019 and spread to entire world quickly. The quick recognition of the problem could have saved life of millions from the dangerous infection. The available diagnostic facilities for the detection of viral infection with SARS-CoV-2 are limited and expensive. There are few tests used for the diagnosis of coronavirus as discussed below.

\subsection{Serological}

The development of disease symptoms is dependent on the viral load as well as the immune status of the patient. Whenever any virus enters in body, the host immune system prepares antibodies to recognize viral antigens. The development of antibodies specific to viral antigens will requires at least two weeks duration from the date of exposure. The serological test 
may help in identifying immune carriers of the disease, who may potentially spread the infectious organism to vulnerable hosts. The diagnosis of COVID-19 infections is also attempted by detecting antibodies [34]. According to ICMR, serological kits that detect antibodies such as IgG and IgM are under trial. Detection of IgM in sample specimen means that the infection is recent. Whereas, the presence of IgG shows that the infection is old. The immunological responses should also be monitored in infected people to understand the virus pathogenesis.

\subsection{Molecular}

The reverse transcriptase polymerase chain reaction (RT-PCR) is molecular diagnostic tool [35]. The cost and availability of expertise are two limiting factors for the RT-PCR. Several researchers have diagnosed human and bat coronavirus infections through laboratory techniques [36-39]. The technique is fast and reliable as it provides positive test result, even if there are very small amount of virion particles present in samples taken from throat or nose of patient. The diagnosis may provide result as early as two days of exposure and prior to appearance of any symptom. Total time required for the test from sample collection to finding test result may be as short as 2-3 hours. However, the RT-PCR is the ultimate test for the detection of this virus. It is also important to understand the effect of possible treatment strategies among childhood, youth and old aged people. There may be effect of gender and age on treatment strategies.

\subsection{Future Surveillance Strategies}

The infection with the emerging infectious agents will always remain a problem for the society. Therefore, exhaustive research on microbiological surveillance is required to be initiated. The governments should raise funds for the regular screening of source of infection. The screening of aquatic and terrestrial animals as well as members of avian species is required. The probable source of infectious agent may be the environment also. Therefore, efforts should be made to do metagenomic analysis of environmental samples to predict the presence of any unknown strain/ or species of bacteria and/or virus, so that such infectious agents may be identified well in advance before they lead an epidemic or pandemic.

\section{PREVENTION}

The virus can be restricted through following the guidelines and advisories of Ministry of Health and Family Welfare, India and the WHO. Frequent practices such as hand hygiene, use of mask, physical distancing, etc. are very effective in prevention of this virus. Preventive measures, stay home and social distancing are helpful in restricting the spread of SARS-CoV-2 infection [40]. There are some factors that are important to monitor for preventing any disease such as the recovery rate, doubling rate of cases and the extent of testing and surveillance for any particular area.

\section{CONCLUSIONS}

COVID-19 pandemic might affect most of Indian population if people avoid the guidelines and advisories of MoHFW India, WHO and CDC. Treatment resources must be enough to control SARS-CoV-2 infections. It is expected that the year 2020 will be challenging for India as well as other countries also. Testing, isolating and treating COVID-19 infected people and tracing their contacts is also challenging. Thus, a robust surveillance strategy based on enhanced testing is required to monitors the geographical spread of COVID-19, changes in age groups, information about the age specific immunity measure the effect on healthcare system and helps in contact tracing. Also, there is an urgent need of expanded testing capacity and effective treatment strategies for restricting COVID-19 infections.

\section{COMPETING INTERESTS}

Authors have declared that no competing interests exist.

\section{REFERENCES}

1. Sahin AR, Erdogan A, Mutlu AP, et al. 2019 Novel coronavirus (COVID-19) outbreak: A review of the current literature. EJMO. 2020;4(1):1-7.

DOI: 10.14744 /ejmo.2020.12220

2. Kahn JS, Mclntosh K. History and recent advances in coronavirus discovery. Ped Infect Dis J. 2005;24(11):223-227.

DOI:10.1097/01.inf.0000188166.17324.60

3. Tyrrell DA, Almeida JD, Cunningham $\mathrm{CH}$, et al. Coronaviridae. Intervirol. 1975;5:7682. 
DOI: https://doi.org/10.1159/000149883

4. Chen Yu, Liu Q, Guo D. Emerging coronaviruses: Genome structure, replication and pathogenesis. J Med Virol. 2020;92(4):418-423.

DOI: $10.1002 / j m v .25681$

5. Prasad N, Kumar A, Tripathi M. Novel coronavirus disease (COVID-19) pandemic in India: a review. EJMI. 2020;4(3):279283.

DOI: 10.14744/ejmi.2020.38479

6. Lai MMC, Holmes KV. Coronaviridae: The viruses and their replication. In: Knipe DM, Howley PM, Griffin DE, Lamb RA, Martin MA, Roizman B, Strais SE (eds): Fields Virology. Lippincott — Williams \& Wilkins, Philadelphia. 2001;1163-1185.

7. Lu R, Zhao X, Li J, et al. Genomic characterization and epidemiology of 2019 novel coronavirus: Implications for virus origins and receptor binding. Lancet. 2020; 395:565-574.

DOI:https://doi.org/10.1016/ S01406736(20)30251-8

8. Du Toit A. Outbreak of a novel coronavirus, Nat. Rev. Microbiol. 2020; 18(123).

DOI:https://doi.org/10.1038/s41579-020-

0332-0

9. Paules I, Marston HD, Fauci AS. Coronavirus infections - more than just the common cold. JAMA. 2020;323(8): 707-708.

DOI: 10.1001/jama.2020.0757

10. Cascella M, Rajnik M, Cuomo A, et al. Features, Evaluation and Treatment Coronavirus (COVID-19), In: Treasure Island (FL): Stat Pearls Publishing; 2020.

Available:https://www.ncbi.nlm.nih.gov/boo ks/NBK554776

11. Neuman BW, Adair BD, Yoshioka C, et al. Supramolecular architecture of severe acute respiratory syndrome coronavirus revealed by electron cryomicroscopy. J Virol. 2006;80(16):7918-7928.

DOI: $10.1128 / J V I .00645-06$

12. Fehr AR, Perlman S. Coronaviruses: an overview of their replication and pathogenesis, In: Coronaviruses: Methods and Protocols, Methods in Molecular Biology (Eds. Maier HJ, Bickerton E, Britton P). Springer. 2015;1282:1-23. DOI:https://doi.org/10.1007/978-1-49397_1

13. Zheng $Y$, Shang J, Yang $Y$, et al. Lysosomal proteases are a determinant of coronavirus tropism. J Virol. 2018;92 (24):e01504-18.

DOI: $10.1128 / J V I .01504-18$

14. Alvaro D, Branch E, Challener CA.

Available:https://www.pharmasalmanac.co m/articles/covid-19-a-look-at-the-virus-itsepidemiology-therapeutic-and-vaccinedevelopment-efforts-and-impacts-of-thepandemic)

(Retrieved on 19 April 2020)

15. WHO

Available:https://www.who.int/emergencies /diseases/novel-coronavirus-

2019/question-and-answers-hub/q-a-

detail/q-a-coronaviruses

(Accessed on 17 April, 2020)

16. CDC.

Available:https://www.cdc.gov/coronavirus/ 2019-ncov/symptoms-

testing/symptoms.html

(Accessed on 13 May, 2020)

17. Doremalen V, Bushmaker Mr, Morris Mr. Aerosol and surface stability of SARSCoV-2 as compared with SARS-CoV-1. N Eng J Med; 2020.

DOI: 10.1056/NEJMc2004973

18. Chan KH, Peiris JSM, Lam SY, et al. The effect of temperature and relative humidity on the viability of the SARS coronavirus. Adv Virol; 2011.

DOI: $10.1155 / 2011 / 734690$

19. Altamimi A, Ahmed AE. Climate factors and incidence of Middle East respiratory syndrome coronavirus. J Inf Pub Hth; 2019.

DOI:https://doi.org/10.1016/j.jiph.2019.11.0 11

20. Zhou $P$, Yang XL, Wang XG, et al. A pneumonia outbreak associated with a new coronavirus of probable bat origin. Nature. 2020;579:270-273.

21. Available:https://www.who.int/docs/defaultsource/coronaviruse/situationreports/20200527-covid-19-sitrep128.pdf?sfvrsn=11720c0a_2, accessed on 28 May, 2020.

22. Rabaan AA, Al-Ahmed SH, Haque $\mathrm{S}$, et al. 2020. SARS-CoV-2, SARS-CoV, and MERS-COV: A comparative overview. Infez Med. 2020;28(2):174-184.

23. Gralinski LE, Baric RS. Molecular pathology of emerging coronavirus infections. J Pathol. 2015;235(2):185-195.

DOI: $10.1002 /$ path.4454

24. Dagur H, Dhakar S. Genome organization of Covid-19 and emerging severe acute 
respiratory syndrome Covid-19 outbreak: A pandemic. EJMO. 2020;4(2):107-115.

DOI: 10.14744/ejmo.2020.96781

25. Le TT, Andreadakis Z, Kumar A, et al. The COVID-19 vaccine development landscape. Nature Rev Drug Dis. 2020; 19:305-306.

DOI: $10.1038 / d 41573-020-00073-5$

26. McKee DL, Sternberg A, Stange $U$, et al. Candidate drugs against SARS-CoV-2 and COVID-19. Pharmacol Res; 2020. DOI: 10.1016/j.phrs.2020.104859

27. Xia S, Liu M, Wang C, et al. Inhibition of SARS-CoV-2 (previously 2019nCoV) infection by a highly potent pancoronavirus fusion inhibitor targeting its spike protein that harbors a high capacity to mediate membrane fusion. Cell Res. 2020;30:343-55.

28. Lin SC, Ho CT, Chuo WH, et al. Effective inhibition of MERS-CoV infection by resveratrol. BMC Infect Dis. 2017; 17(1):144.

DOI:https://doi.org/10.1186/s12879-0172253-8

29. Kampf G, Todt D, Pfaender S, et al. Persistence of coronaviruses on inanimate surfaces and their inactivation with biocidal agents. J Hospial Inf. 2020;104:246-251. DOI: https://doi.org/10.1016/j.jhin.2020.01. 022

30. Parsons L. Takeda begins development of COVID-19 plasma therapy. PMLiVE; 2020.

31. Ali O, Yasin I. ACE 2 in the context of COVID 19- An opportunity for us or the virus. EJMO. 2020;4(2):137-138.

DOI: 10.14744/ejmo.2020.87844

32. Rahmati M, Moosavi M. Cytokine-targeted therapy in severely ill COVID-19 patients: options and cautions. EJMO. 2020;4(2): 179-181.

DOI:10.14744/ejmo.2020.72142

33. Kumar V, Dhanjal JK, Kaul SC, et al. Withanone and caffeic acid phenethyl ester are predicted to interact with main protease $\left(\mathrm{M}^{\mathrm{pro}}\right)$ of SARS-CoV-2 and inhibit its activity. J Biomol Stru Dyn; 2020.

DOI:https://doi.org/10.1080/07391102.202 0.1772108

34. Li X, Geng M, Peng Y, et al. Molecular immune pathogenesis and diagnosis of COVID-19. J Pharm Anal. 2020;10:102108. DOI:https://doi.org/10.1016/j.pha.2020.03. 001

35. Gupta N, Potdar V, Praaraj I, et al. Laboratory preparedness of SARS-CoV2 testing in India: harnessing a network of virus research and diagnostic laboratories. Indian J Med Res; 2020.

DOI: 10.4103/ijmr.IJMR_594_20

36. Loeffelholz MJ, Tang $\mathrm{Y}-\overline{\mathrm{W}}$. Laboratory diagnosis of emerging human coronavirus infections-the state of the art. Emerg Infect Dis. 2020;9:747-756.

DOI: 10.1080/22221751.2020.1745095

37. Yadav P, Shete-Aich A, Nyayanit DA, et al. Detection of coronaviruses in Pteropus \& Rousettus species of bats from different States of India. Indian J Med Res; 2020.

DOI: 10.4103/ijmr.IJMR_763_20

38. Mourya DT, Sapkal G, Yadav PD, et al. Biorisk assessment for infrastructure \& biosafety requirements for the laboratories providing coronavirus SARS-CoV2/(COVID-19) diagnosis. Indian J Med Res; 2020.

DOI: 10.4103/ijmr.IJMR_763_20

39. Hafeez A, Ahmad S, Siddqui S, et al. A review of COVID-19 (coronavirus disease2019) diagnosis, treatments and prevention. EJMO. 2020;4(2):116-125. DOI: 10.14744/ejmo.2020.90853

40. Available:https://www.who.int/southeastasi a/outbreaks-and-emergencies/novelcoronavirus-2019/protective-measures (Accessed on 31 March, 2020)

(c) 2020 Tripathi and Kumar; This is an Open Access article distributed under the terms of the Creative Commons Attribution License (http://creativecommons.org/licenses/by/4.0), which permits unrestricted use, distribution, and reproduction in any medium, provided the original work is properly cited. http://www.sdiarticle4.com/review-history/57987 